\title{
Oral Mechanism/Cranial Nerve Examination for Young Children
}

National Cancer Institute

\section{Source}

National Cancer Institute. Oral Mechanism/Cranial Nerve Examination for Young Children. NCI Thesaurus. Code C160859.

A clinical protocol developed for the purpose of assessing the oral and speech motor abilities of children. The protocol can be administered in 7-10 minutes, and a child's performance can be compared to developmental norms. 